\title{
Efficacy of Drotaverine in Comparison to Hyoscine Butylbromide in Augmentation of Labour
}

\author{
Sameena Ashraf Kirmani, M.D., ${ }^{1}$ Mohd Sadiq Malla, M.D., ${ }^{2}$ Farkhand Mohi-ud-din Regoo, M.D. ${ }^{3}$ \\ 'Lal Ded Hospital, GMC Srinagar, ${ }^{2}$ Department of Anaesthesiology SKIMS, Soura, Srinagar, ${ }^{3}$ SMHS Hospital, Srinagar
}

\section{A B S T R A C T}

\begin{abstract}
BACKGROUND: Contractility of the myometrium is usually diminished during pregnancy to accommodate and protect the growing products of conception; drugs like Hyoscine butylbromide and Drotaverine are used to shorten the duration of labor in many hospitals all over the world.

OBJECTIVE: To compare the effect of intravenous Drotaverine and Hyoscine Butylbromide rectal suppository on duration of labour and rate of cervical dilatation.

METHODS: Three hundred pregnant women with term pregnancy in active labour were selected by simple randomization and were divided into three groups: Group A, where injection Drotaverine intravenous was given; Group B, where Hyoscine Butylbromide rectal suppository was instilled; and in Group C, where no drug was given.

RESULTS: Mean duration of first stage of labour was $179.1 \mathrm{~min}, 159.3 \mathrm{~min}$ and $299.0 \mathrm{~min}$ in groups A, B and C, respectively. Rate of cervical dilatation in groups $A, B$ and $C$ was $2.6,2.9$ and $2.0 \mathrm{~cm} / \mathrm{hr}$, respectively. Most of the subjects delivered vaginally. No serious side effects were noted in both the drug groups.

CONCLUSION: Hyoscine Butylbromide is more effective than Drotaverine in reducing the duration of active phase of labour. There is a significant improvement in the rate of cervical dilatation with Hyoscine Butylbromide when compared to Drotaverine. JMS 2012;15(1):39-43.
\end{abstract}

Key words: Hyoscine Butylbromide; Drotaverine; Cervical dilatation; Labour

During pregnancy the contractility of the myometrium is usually diminished to accommodate and protect the growing products of conception, whereas the cervix forms a tight sphincter to ensure the integrity of pregnancy. ${ }^{1}$ Close to term, myometrial activity increases and the cervix undergoes biochemical changes, so called cervical maturation and ripening. Cervix plays essentially a passive role as an innocent

\section{Correspondence:}

Dr. Sameena Ashraf Kirmani,

M.D (Gyne \& Obestet.)

Registrar Lal Ded Hospital.

E-Mail: saminadrgmc@gmail.com

Phone no: 9596278910 obstruction and is acted upon by all the forces of labour. Cervical dilatation is the resultant of all the driving forces of uterine contractions acting against passive tissue resistance. The dilatation of the cervix is one of the effective end results of these forces and in this role it serves to reflect the process of labour. ${ }^{1}$ In spite of good uterine contractions the cervical dilation may be hampered because of inhibitory impulses in the form of spasm leading to prolonged labour. In such cases antispasmodics help in the dilatation of cervix. Various drugs have been used so far to obtain effective dilatation of the internal os, majority of them were found to have its effect on the foetus and mother. Modern Obstetricians are now in search of new drugs, which have got the sole beneficiary effect on the dilatation of the internal os with minimal side effects on foetus 
and the mother. Two such antispasmodic drugs are Hyoscine butylbromide and Drotaverine which have been used to shorten the duration of labor in many hospitals all over the world.

Drotaverine, an isoquinoline derivative, is a phosphodiesterase (PDE) inhibitor and is selective for type IV isoenzyme. It acts specifically on spastic sites and corrects the cAMP and calcium balance relieving smooth muscle spasm. ${ }^{2}$ This action is thought to facilitate cervical dilatation. Leroy et al. ${ }^{3}$ found that in the third trimester and near term, a high concentration of PDE type IV is seen in the human myometrium. This predominance may suggest its role in labour. This spasmolytic action is thought to be the mechanism for facilitating cervical dilatation.

Hyoscine butylbromide is a quaternary ammonium derivative, which exerts a spasmolytic action on the smooth muscle of the gastrointestinal, biliary, and genitourinary tracts. ${ }^{4}$ Hyoscine butylbromide belongs to a parasympatholytic group of drugs and it is a semisynthetic derivative of scopolamine, it has effective antispasmodic activity but devoid of side effects of atropine, it does not cross the blood brain barrier, it acts primarily by blocking the transmission of neural impulses in the parasympathetic ganglia of abdominal organs. ${ }^{5}$ This study is an attempt to compare and evaluate the efficacy of Drotaverine hydrochloride and Hyoscine butylbromide in the process of cervical dilatation and labour augmentation.

\section{Methods}

It was a randomized, comparative, prospective study carried out at Government Lal Ded Hospital, an associated hospital of GMC. Total of 450 women with term gestation, in active labour were chosen by simple randomization from the admission to the labour ward for the administration of drugs and written informed consent for the same was taken. The patients were divided into 3 groups, each having 150 women: group I (received intravenous injection Drotaverine), group II (received Hyoscine Butylbromide rectal suppository) and group III (received no drug). Following inclusion and exclusion criteria were considered for selection of the subjects. Patients included were primigravida and multigravida with age between 18-30 year, intact fetal membranes, vertex presentation, regular established uterine contraction at the rate of at least 2/10 minute, each contraction lasting for at least 20 seconds, cervical dilatation of 3-4 cms and no evidence of maternal or fetal distress. Patients with malpresentation, twin pregnancy, cervical surgery in the past or history of cervical injury, induced labor, maternal systolic pressure below $100 \mathrm{~mm} \mathrm{Hg}$ or above $150 \mathrm{~mm} \mathrm{Hg}$, patients on antihypertensive therapy, known hypersensitivity to Drotaverine or Hyoscine butylbromide and if any other spasmolytic agent had been used within 48 hours were excluded from the study.

On entry into the study a detailed history of the subjects was taken. A thorough general and systemic examination was done. Per abdomen examination was done to note height of the uterus, presentation, frequency and intensity of contractions.
Fetal wellbeing was monitored by noting the rate, rhythm and regularity of fetal heart sounds. By per vaginum examination cervical dilatation, effacement and consistency and station of the presenting part were noted. Pelvic assessment was done to exclude any pelvic contraction or cephalopelvic disproportion etc. Per vaginal examination was done before giving each dose of the drug or if rupture of membranes occurred or patients started bearing down. Routine investigations were advised including $\mathrm{Hb}$, BT, CT, blood grouping, blood sugar, HIV, HBSAg and VDRL, urine for routine and microscopic examination.

The drug administration was done in patients with established labor i.e., at 3 or $4 \mathrm{~cm}$ cervical dilatation with regular uterine contractions of $>2$ per 10 min each lasting 20 seconds. In Group A cases received intravenous Drotaverine $40 \mathrm{mg}$. Injection was repeated after 2 hours as per cervical dilations to a maximum of 3 injections. In Group B 10mg rectal suppository was put in the rectum of the cases. The drug was repeated every hour up to a maximum of three doses depending upon the cervical dilatation. In Group C no drug was given and represented the control group. All women were monitored for pulse, temperature, respiratory rate, blood pressure, foetal heart rate and adverse reactions every $30 \mathrm{~min}$ in the first stage and every $5 \mathrm{~min}$ in the second stage. Medical staff delivered all the babies. Caesarean section or assisted vaginal delivery was conducted for obstetric indications.

Following parameters were recorded in every patient-

- Duration of first, second and third stages of labour.

- Rate of cervical dilatation

- Mode of delivery

- Neonatal condition at birth.

- Side effects of drugs

- Maternal complications

\section{Statistical Analysis}

Parametric data was expressed as mean \pm SD, thereby the inter group comparisons were made by student's t-test and ANOVA. The non-parametric data was represented in percentage, thereby the inter group comparisons were made by Mann-Whitney U test and Kruskal Wallis test. Significance was checked at 95\% CI. SPSS 19.0 software was used for data analysis.

\section{Results}

Table 1 shows demographic characteristics of the women in Drotaverine, Hyoscine butylbromide and Control groups. There was no statistical difference in the three groups in age, gestational age, parity and cervical dilatation at admission.

As shown in Table 2, the duration of first stage of labour $(159.3 \pm 40.9 \mathrm{~min})$ in the Hyoscine butylbromide group was statistically lower than the Drotaverine group (179.1 \pm 46.8 $\mathrm{min})$ and the control group $(299.0 \pm 86.0 \mathrm{~min})$. The duration of first stage of labour in the Drotaverine group was lesser than the control group and was statistically significant. The differ- 
Table 1. Demographic characteristics of the women in various groups

\begin{tabular}{|c|c|c|c|c|}
\hline Variables & $\begin{array}{c}\text { Drotaverine } \\
\text { (Group A) }\end{array}$ & $\begin{array}{c}\text { Hyoscine } \\
\text { butylbromide } \\
\text { (Group B) }\end{array}$ & $\begin{array}{l}\text { Control } \\
\text { (Group C) }\end{array}$ & Pvalue \\
\hline Age (years) & $\begin{array}{c}24.9 \pm 3.2 \\
(20,30)\end{array}$ & $\begin{array}{c}24.8 \pm 3.0 \\
(20,30)\end{array}$ & $\begin{array}{c}25.0 \pm 3.3 \\
(20,30)\end{array}$ & $\begin{array}{l}\text { a: } 0.869, \text { b: } 0.728, \\
\text { c: } 0.608, F: 0.872\end{array}$ \\
\hline $\begin{array}{l}\text { Gestational age } \\
\text { (weeks) }\end{array}$ & $\begin{array}{c}38.5 \pm 1.1 \\
(37,40)\end{array}$ & $\begin{array}{c}38.5 \pm 1.1 \\
(37,40)\end{array}$ & $\begin{array}{c}38.5 \pm 1.1 \\
(37,40)\end{array}$ & $\begin{array}{l}\text { a: } 0.715, \text { b: } 0.835, \\
\text { c: } 0.876, F: 0.935\end{array}$ \\
\hline $\begin{array}{c}\text { Primigravida } \\
\text { N (\%) }\end{array}$ & $55(36.7 \%)$ & $59(39.3 \%)$ & 57 (38\%) & $\begin{array}{l}\text { a: } 0.635, b: 0.812, \\
c: 0.813, F: 0.893\end{array}$ \\
\hline $\begin{array}{c}\text { Multigravida } \\
\mathrm{N}(\%)\end{array}$ & 9516 & $91(60.7 \%)$ & $93(62 \%)$ & \\
\hline $\begin{array}{l}\text { Initial cervical } \\
\quad \text { dilatation }(\mathrm{cm})\end{array}$ & $\begin{array}{c}3.6 \pm 0.5 \\
(3,4)\end{array}$ & $\begin{array}{c}3.6 \pm 0.5 \\
(3,4)\end{array}$ & $\begin{array}{c}3.5 \pm 0.5 \\
(3,4)\end{array}$ & $\begin{array}{l}a: 0.817, b: 0.247, \\
c: 0.165, F: 0.330\end{array}$ \\
\hline
\end{tabular}

Values are expressed as mean \pm standard deviation (maximum, minimum)

$a$ : comparison between Drotaverine and Hyoscine butylbromide; $b$ : comparison between Drotaverine and Control; c: comparison between Hyoscine butylbromide and Control; F: ANOVA (overall comparison)

Table 2. Labor characteristics of the women in various groups.

\begin{tabular}{|c|c|c|c|c|}
\hline Variables & $\begin{array}{l}\text { Drotaverine } \\
(\mathrm{N}=100)\end{array}$ & $\begin{array}{l}\text { Hyoscine } \\
\text { butylbromide } \\
(\mathrm{N}=100)\end{array}$ & $\begin{array}{l}\text { Control } \\
(\mathrm{N}=100)\end{array}$ & Pvalue \\
\hline $\begin{array}{l}\text { Mean Total } \\
\text { duration of } \\
\text { labour (min) }\end{array}$ & $\begin{array}{c}212.1 \pm 49.8 \\
(123,318)\end{array}$ & $\begin{array}{c}191.2 \pm 42.5 \\
(118,274)\end{array}$ & $\begin{array}{c}332.5 \pm 88.1 \\
(163,503)\end{array}$ & $\begin{array}{l}a: 0.004, b: 0.000, \\
c: 0.000, F: 0.000\end{array}$ \\
\hline $\begin{array}{c}\text { Mean duration of } \\
\text { first stage of } \\
\text { labour (min) }\end{array}$ & $\begin{array}{c}179.1 \pm 46.8 \\
(105,260)\end{array}$ & $\begin{array}{c}159.3 \pm 40.9 \\
(90,228)\end{array}$ & $\begin{array}{c}299.0 \pm 86.0 \\
(146,445)\end{array}$ & $\begin{array}{l}a: 0.005, b: 0.000, \\
c: 0.000, F: 0.000\end{array}$ \\
\hline $\begin{array}{l}\text { Mean duration of } \\
\text { second stage of } \\
\text { labour (min) }\end{array}$ & $\begin{array}{c}25.9 \pm 14.0 \\
(4,50)\end{array}$ & $\begin{array}{c}24.9 \pm 11.3 \\
(6,44)\end{array}$ & $\begin{array}{c}26.8 \pm 13.1 \\
(5,50)\end{array}$ & $\begin{array}{l}a: 0.496, b: 0.566, \\
c: 0.210, F: 0.454\end{array}$ \\
\hline $\begin{array}{l}\text { Mean duration of } \\
\text { third stage of } \\
\text { labour (min) }\end{array}$ & $\begin{array}{c}7.1 \pm 2.1 \\
(4,10)\end{array}$ & $\begin{array}{c}7.0 \pm 1.9 \\
(4,10)\end{array}$ & $\begin{array}{c}6.7 \pm 1.9 \\
(4,10)\end{array}$ & $\begin{array}{l}\text { a: } 0.723, \text { b: } 0.072, \\
\text { c: } 0.148, F: 0.162\end{array}$ \\
\hline $\begin{array}{l}\text { Rate of cervical } \\
\text { dilatation }(\mathrm{cm} / \mathrm{hr})\end{array}$ & $\begin{array}{c}2.6 \pm 1.1 \\
(2,8)\end{array}$ & $\begin{array}{c}2.9 \pm 1.2 \\
(2,8)\end{array}$ & $\begin{array}{c}2.0 \pm 0.8 \\
(2,6)\end{array}$ & $\begin{array}{l}a: 0.028, b: 0.000, \\
c: 0.000, F: 0.000\end{array}$ \\
\hline $\begin{array}{l}\text { Mode of delivery } \\
\quad \mathrm{N}(\%) \\
\text { - } \quad \text { Vaginal delivery }\end{array}$ & y 138 ( & $138(92 \%)$ & $135(90 \%)$ & \\
\hline $\begin{array}{c}\text { Instrumental } \\
\text { delivery }\end{array}$ & $6(4 \%)$ & $7(4.7 \%) 7$ & $(4.7 \%)$ & $\begin{array}{l}a: 0.986, b: 0.541 \text {, } \\
c: 0.528, F: 0.766\end{array}$ \\
\hline LSCS & $6(4 \%)$ & $5(3.3 \%) 8$ & $(5.3 \%)$ & \\
\hline
\end{tabular}

Values are expressed as mean \pm standard deviation (maximum, minimum)

$a$ : comparison between Drotaverine and Hyoscine butylbromide; $b$ : comparison between Drotaverine and Control; c: comparison between Hyoscine butylbromide and Control; F: ANOVA (overall comparison)

ences in the duration of second and third stages of labour in the three groups respectively were not statistically significant The cervical dilatation rate, as shown in Table 2 , was statistically higher in the Hyoscine butylbromide group $(2.9 \pm 1.2 \mathrm{~cm} / \mathrm{h})$, compared to Drotaverine $(2.6 \pm 1.1 \mathrm{~cm} / \mathrm{h})$ and the control group $(2.0 \pm 0.8 \mathrm{~cm} / \mathrm{h})$. The rate of cervical dilatation in the Drotaverine group was statistically higher than the control group.

As far as the mode of delivery is concerned, $92 \%, 92 \%$ and $90 \%$ delivered by normal vaginal delivery in Drotaverine, Hyoscine butylbromide and control groups respectively. There was $4 \%, 4.7 \%$ and $4.7 \%$ instrumental delivery in group $\mathrm{A}, \mathrm{B}$ and $\mathrm{C}$ respectively. The indication being foetal distress and prolonged II stage of labour in most of the cases. LSCS was performed in $4 \%, 3.3 \%$ and $5.3 \%$ of women in the three groups respectively. The indication being arrest of labour in most of the cases and fetal distress in a few cases.

Side effects were noted in all the groups and were transient and self-limiting. There were no serious untoward events noted in any of the groups (Table 3). As far as the complications during delivery process were concerned, no significant association was observed between groups and complications.

As shown in Table 4, there was no significant difference in the birth weight in three groups. There was also no statistical difference in the APGAR scores noted at 1 and 5 minutes in the three groups.

Table 3. Side Effects of drugs and Complications found in women in various groups

\begin{tabular}{|c|c|c|c|c|}
\hline Variables & $\begin{array}{l}\text { Drotaverine } \\
\text { (N\%) }\end{array}$ & $\begin{array}{c}\text { Hyoscine } \\
\text { butylbromide } \\
\text { (N\%) }\end{array}$ & $\begin{array}{l}\text { Control } \\
\text { (N\%) }\end{array}$ & Pvalue \\
\hline $\begin{array}{l}\text { Maternal } \\
\quad \text { Tachycardia }\end{array}$ & $2(1.3) 1$ & (0.7) & - & $\mathrm{a}: 0.562, \mathrm{~b}: 0.157, \mathrm{c:}: 0.317$ \\
\hline $\begin{array}{l}\text { Eoetal } \\
\quad \text { Tachycardia }\end{array}$ & $2(1.3)$ & $3(2.0)$ & $1(0.7)$ & $\mathrm{a}: 0.653, \mathrm{~b}: 0.562, \mathrm{c}: 0.315$ \\
\hline $\begin{array}{c}\text { ryness of } \\
\text { Mouth }\end{array}$ & $2(1.3)$ & $3(2.0)$ & $2(1.3)$ & $\mathrm{a}: 0.653, \mathrm{~b}: 1.000, \mathrm{c:} 0.653$ \\
\hline Nausea/Vomiting & $1(0.7)$ & $2(1.3)$ & - & $a: 0.562, b: 0.317, c: 0.157$ \\
\hline Flushing & $3(2.0)$ & $2(1.3)$ & $1(0.7)$ & $a: 0.653, b: 0.315, c: 0.562$ \\
\hline Foetal Distress & $9(6.0)$ & $8(5.3)$ & $11(7.3)$ & $\mathrm{a}: 0.803, \mathrm{~b}: 0.478, \mathrm{c}: 0.644$ \\
\hline Birth Asphyxia & $3(2.0)$ & $2(1.3)$ & $1(0.7)$ & $\mathrm{a}: 0.653, \mathrm{~b}: 0.315, \mathrm{c}: 0.562$ \\
\hline Meconium & $3(2.0)$ & $2(1.3)$ & $2(1.3)$ & $\mathrm{a}: 0.653, \mathrm{~b}: 0.653, \mathrm{c}: 1.000$ \\
\hline $\begin{array}{l}\text { Prolonged Second } \\
\text { Stage of labour }\end{array}$ & $r \quad 4(2.7)$ & $6(4.0)$ & $4(2.7)$ & $\mathrm{a}: 0.521, \mathrm{~b}: 1.000, \mathrm{c}: 0.521$ \\
\hline Vaginal Tear & $1(0.7)$ & $1(0.7)$ & $2(1.3)$ & $a: 1.000, b: 0.562, c: 0.562$ \\
\hline
\end{tabular}

Values are expressed as mean \pm standard deviation (maximum, minimum)

$a$ : comparison between Drotaverine and Hyoscine butyl bromide; b: comparison between Drotaverine and Control; c: comparison between Hyossine butyl bromide and Control; F: ANOVA (overall comparison)

\section{Discussion}

The subject of cervical dilatation and progress of labor has puzzled obstetricians for a long time, with prolonged labor having implications for both the mother and the fetus. Acceleration of labor is considered to be an important factor in reducing maternal morbidity as well as the neonatal complications. Several drugs like antispasmodics, tranquillizers, 
Table 4. Neonatal outcome of women in various groups

$\begin{array}{ccccc}\text { Variables } & \text { Drotaverine } & \begin{array}{c}\text { Hyoscine } \\ \text { butylbromide }\end{array} & \text { Control } & \text { Pvalue } \\ \text { Birth weight }(\mathrm{kg}) & 2.9 \pm 0.4 & 2.9 \pm 0.4 & 2.9 \pm 0.4 & \mathrm{a}: 0.472, \mathrm{~b}: 0.188, \\ & (2.2,3.6) & (2.2,3.6) & (2.2,3.7) & \text { c: } 0.550, \mathrm{~F}: 0.419 \\ \text { Apgar score } & 6.9 \pm 0.8 & 7.0 \pm 0.8 & 7.0 \pm 0.8 & \mathrm{a}: 0.576, \mathrm{~b}: 0.294, \\ \text { at 1min } & (6,8) & (6,8) & (6,8) & \text { c: } 0.624, \mathrm{~F}: 0.576 \\ \text { Apgar score } & 9.1 \pm 0.9 & 9.1 \pm 0.9 & 9.2 \pm 0.9 & \mathrm{a}: 0.474, \mathrm{~b}: 0.269 \text {, } \\ \text { at 5min } & (8,10) & (8,10) & (8,10) & \text { c: } 0.696, \mathrm{~F}: 0.533\end{array}$

Values are expressed as mean \pm standard deviation (maximum, minimum)

$a$ : comparison between Drotaverine and Hyoscine butyl bromide; $b$ : comparison between Drotaverine and Control; c: comparison between Hyoscine butyl bromide and Control; F: ANOVA (overall comparison)

prostaglandins and psychotherapeutic methods have been tried in the past to facilitate cervical dilatation and hence augment labour, but majority of these were found to have ill effect on the mother and the fetus. Hyoscine butylbromide and Drotaverine are two antispasmodic drugs which are safe and effective in shortening duration of labor. In the present study we compared the effect of I.V Drotaverine and Hyoscine butylbromide rectal suppository on duration of labour and rate of cervical dilatation. It was seen that both the drugs have been found to shorten the duration of first stage of labour, but it was significant shorter in the Hyoscine butylbromide group than the Drotaverine group. No serious maternal or fetal side effects were observed with both the drugs. There was no difference in mode of delivery, birth weight of the neonates and their Apgar score at $1 \mathrm{~min}$ and $5 \mathrm{~min}$. similar observations were made in previous studies.

Hector Mario Barachio et al. ${ }^{6}$ conducted a study using buscopan for labour augmentation and reported shortening of first stage of labour by 1 hour 32 mins in primigavidae and 1 hour 27 mins in multigravidae and total duration of labour by 2 hours and $1 \mathrm{~min}$ in primigavidae without any untoward side effects either on the mother or the foetus. Bhattacharya et al. ${ }^{7}$ conducted a study using Buscopan for acceleration of first stage of labour and noted that the duration of first stage of labour was shortened by 3 hours and 40 mins. Also they noted that it has no adverse action on newborns and the side effects on the mothers are also not serious.

Samal $e t$ al $^{8}$ in a similar study reported shortening of labour by 2 hours 42 minutes with $88 \%$ women delivering within 8 hours following Buscopan administration. No serious side effects were noticed on mother and foetus.

Tewari et al in a similar study found labour to be shortened by 5 hours 12 minutes as compared with controls following the administration of Buscopan. A recent study from Jamaica also showed shortening of first stage of labour by $32 \%$, without any adverse effect on mother or neonate, with $20 \mathrm{mg}$ intravenous dose. ${ }^{10}$

Poornima R Ranka et $a l^{11}$ conducted a similar study using Drotaverine for acceleration of first stage of labour and found that total duration of labour was shortened by $62 \mathrm{mins}$, Duration of active phase of 1st stage shortened by 60 mins, duration of 2 nd and 3 rd stage differed only by 4 mins and there was no serious side effects noticed on mother and foetus.

Gupta Ket al ${ }^{12}$ did 535 cases of delivery with Drotaverine. They concluded that Drotaverine is effective in reducing the duration of labour by hastening cervical dilatation. It is more effective when membrane has been ruptured. It is also found that Drotaverine does not increase in the incidence of operative delivery.

Muralidhar V Pai et $a l^{13}$ reported that after $40 \mathrm{mg}$ of Drotaverine was administered intramuscularly on 141 labouring patients, mean duration of active phase was reduced by $17.3 \%$ in primi patients given Drotaverine, whereas in multigravidae there was $15.6 \%$ reduction as compared with controls which were not given any drug. Equal number of women delivered spontaneously in both the groups. They concluded that Drotaverine is more effective when the membranes have ruptured either spontaneously or by amniotomy.

We conclude that both Drotaverine and Hyoscine butylbromide are effective in shortening duration of labour without any significant detrimental effects to the mother and the new born. But Hyoscine butylbromide dilates the cervix more rapidly than Drotaverine and the duration of active phase was shorter in Hyoscine butylbromide group than Drotaverine group. Hyoscine butylbromide, because of its convenience of administration (as rectal suppository) can be a comparable alternative in rural setups where trained medical personnel may not be available most of the times. Hyoscine butylbromide is better in achieving the end result. Hence it can be used in modern obstetrics to relieve spasm and to hasten the rate of cervical dilatation and thereby promoting safe delivery.

\section{References}

1. Phyllis C Leppert. Anatomy and physiology of cervical ripening. Clin Obstet Gynaecol 1995;38(2):267-78.

2. Gupta K. Emerging role of drotaverine in emergency medicine: A review.J Am Med Assoc Ind Physicians' Update 1999;2:57-64.

3. Leroy MI et al. Isolation and characterization of the rolipram sensitive cAMP speciWc phophodiesterase (Type IV PDE) in human myometrium. Cell Signal 1994; 6:405-12.

4. Drug Information: Buscopan. Ingelheim, Germany: Boehringer Ingelheim Limited. Revised December 2005.

5. Sirohiwal D, Dahiya K. Efficacy of hyoscine-N-butyl bromide (Buscopan) suppositories as a cervical spasmolytic agent in labour. Aust N Z J Obstet Gynaecol 2005;45:128-9. 
6. Barachio HM, Kamath J, Kunkalekar K, Jacob C. Hyoscine N - Butyl Bromide in acceleration of labour. $J$ Obstet Gynaecol Ind 1984;34(3):510-13.

7. Bhattacharya P, Joshi SG. Acceleration of labour by intramuscular of Buscopan injection. J of Obstet Gynecol of Ind 1985;35:1014-7.

8. Samal S, Uma Gupta, Wable Hyoscine W. N. Butyl Bromide in acceleration of labour. IMG 1998;132: 8-10.

9. Tewari K, Jabeen R, Sabsposh MA, Rabbani T. Comparison of hyoscine butylbromide and valethemate bromide in shortening of duration of labour. Indian Med Gaz 2003;137:15-9.
10. Samuels LA, Christie L, Roberts-Gitten B, Fletcher H, Frederick J. The effect of hyoscine butylbromide on the first stage of labor in term pregnancy. BrJ Obstet Gynecol 2007;114:1542-6.

11. Poornima R. Ranka. Varsha A. Hishikar: Effects of Drotaverine Hydrochloride on Normal Labour - A Randomized study. J Obstet Gynaec Ind 2002; 52(6): 28-30.

12. Gupta K, Mukharjee K, Chowdhary B. Effect of Drotaverine on the first stage of labour. Obs $\&$ Gynae Today 2003; 8(3).

13. Muralidhar V Pai, SreeLatha Sreekumar, Krishnendu Gupta, Namitha Chatterjee. Effect of Drotaverine on active phase of labour. Obs and Gynae Today 2003 March; VIIII(3). 